\title{
TITLE:
}

\section{Clean coal use in China: Challenges and policy implications}

$\operatorname{AUTHOR}(\mathrm{S})$ :

Tang, Xu; Snowden, Simon; McLellan, Benjamin C.; Höök, Mikael

\section{CITATION:}

Tang, Xu ...[et al]. Clean coal use in China: Challenges and policy implications. Energy Policy 2015, 87: 517-523

\section{ISSUE DATE:}

2015-12

URL:

http://hdl.handle.net/2433/246270

\section{RIGHT:}

(C) 2015. This manuscript version is made available under the CC-BY-NC-ND 4.0 license http://creativecommons.org/licenses/by-nc-nd/4.0/:; この論文は出版社版でありません 。引用の際には出版社版をご確認ご利用ください。; This is not the published version. Please cite only the published version. 


\title{
Clean coal use in China: challenges and policy implications
}

\author{
Xu Tang ${ }^{a^{*}}$, Simon Snowden ${ }^{\mathrm{b}}$, Benjamin C. McLellan ${ }^{\mathrm{c}}$, Mikael Höök ${ }^{\mathrm{d}}$ \\ a School of Business Administration, China University of Petroleum, Beijing 102249, China \\ b Management School, University of Liverpool, Liverpool L69 7ZH, England \\ c Graduate School of Energy Science, Kyoto University, Yoshida-honmachi, Sakyo-ku, Kyoto,
}

606-8501, Japan

d Global Energy Systems, Department of Earth Sciences, Uppsala University, Villavägen 16, SE752 36, Uppsala, Sweden

* Corresponding Author. Tel.:+ 86-10-89731507; Fax: +86-10-89731752.

E-mail address: tangxu2001@163.com (X. Tang).

Abstract: Energy consumption in China is currently dominated by coal, a major source of air pollution and carbon emissions. The utilization of clean coal technologies is a likely strategic choice for China at present, however, although there have been many successes in clean coal technologies worldwide, they aren't widely used in China. This paper examines the challenges that China faces in the implementation of such clean coal technologies, where the analysis shows that those drivers that have a negative bearing on the utilization of clean coal in China are mainly nontechnical factors such as the low legal liability of atmospheric pollution related to coal use, and the lack of laws and mandatory regulations for clean coal use in China. Policies for the development of clean coal technologies are in their early stages in China, and the lack of laws and detailed implementation requirements for clean coal require resolution in order to accelerate China's clean coal developments. Currently, environmental pollution has gained widespread attention from the wider Chinese populace and taking advantage of this opportunity provides a space in which to regain the initiative to raise people's awareness of clean coal products, and improve enterprises' enthusiasm 
for clean coal.

Keywords: Clean Coal; Coal Consumption; Environmental Challenge; Energy Administration

*Corresponding author. Tel.: 86-10-89731507; fax: 86-10-89731752.

E-mail address: tangxu2001@163.com (X. Tang).

\section{Introduction}

Economic growth benefits from abundant and cheap sources of energy, and in China - the world's largest developing country as well as a global factory - the present clear choice for such a source of abundant and cheap energy is coal. Coal currently dominates the supply and consumption of energy in China (Fig.1), accounting for $75.6 \%$ of total energy production and $66.0 \%$ of total energy consumption in 2013(National Bureau of Statistics of China, 2014), and coal is particularly critical for the power sector, generating about $80 \%$ of China's total electricity output (Shealy and Dorian,2010).

There is a close relationship between economic growth and coal consumption in China with coal consumption rising as the economy and industry expand (Fig.2). Ma et al. (2010) undertook a comprehensive literature review on this topic. Many of the reviewed studies demonstrate a causal relationship between national aggregate energy consumption and national aggregate economic growth in China, and the causal relations can be classified into three groups: (1) Energy consumption Granger causes economic growth; (2) Economic growth Granger causes energy consumption; (3) Economic growth and energy consumption Granger cause each other. With a more detailed focus, He et al. (2008) found that the causal relationship between energy consumption and economic growth is significant only in secondary industries. Different findings emerge because econometric analysis results on causal relations have been greatly affected in China by variations in methods 
used, time periods studied and, importantly, data sources (Ma et al., 2010). In recent studies, the Granger causality test for China reveals that there is a bi-directional causality between economic growth and coal consumption in both the short-term and long-term (Govindaraju and Tang, 2013). Further supporting this conclusion, Sheng et al. (2014) employed an instrumental regression technique to verify the positive relationship between economic growth and energy demand in China. Although energy from non-fossil fuels will account for 15\% of total energy use by 2020 according to the Chinese government's renewable energy medium and long-term development plan (NDRC, 2007), fossil fuels will still be the mainstay of China's energy mix in 2020. As for the supply of fossil fuels, China's oil production has remained relatively stable throughout the last decade, and most of the giant oil fields in China, such as Daqing and Shengli, have reached peak production as indicated by Pang et al (2009), Höök et al. (2010) and Tang et al. (2010), leaving an increasingly limited opportunity to further develop domestic oil production. Although natural gas production has increased rapidly in recent years, it makes up only a few percent of China's energy supply system currently, and domestic gas resources cannot be developed quickly enough to match China’s surging gas demand, as highlighted by Li et al. (2011) and Lin and Wang (2012). Under such conditions, coal will remain a major component of energy production in the foreseeable future owing to its domestic abundance in China (You and Xu, 2010).

In recent years, serious haze has become a hot topic for not only the government but also the public in China ( $\mathrm{Li}$ and Zhang, 2014). Most air pollution in China is a result of coal combustion, with coal being the source of $90 \%$ of the $\mathrm{SO}_{2}$ emissions, $70 \%$ of the dust emissions and $67 \%$ of the $\mathrm{NO}_{\mathrm{x}}$ emissions (Chen and $\mathrm{Xu}, 2010$ ). The results of analysis show coal consumption causing pollution, whilst renewable energy consumption reduces pollution (Bloch et al., 2015), and coal- 
dominated energy structures are the main reason for atmospheric pollution (Boden et al., 2013).

In fact, on the consumption side, China is trying to constrain coal consumption and reduce its percentage in the energy mix due to considerations of environmental factors. However, this does not always work in practice, as has become apparent over the last decade. According to China's official 11th Five-year Plan (2006-2010), coal demand was expected to be 2.56Gt in 2010, significantly lower than the actual rate of coal consumption of 3.22Gt (National Bureau of Statistics of China, 2014). Wang et al (2014) reviewed estimated levels of coal consumption from Chinese scholars, taking the results from literature before 2010 as an example, in which almost all of the published papers undervalued China's coal consumption with an average estimation of 2.32Gt for 2010, 28\% lower than the actual coal consumption rates. The industrial sector (manufacturing), especially heavy industries such as iron and steel and cement industries, are responsible for the majority of China’s coal consumption and its growth during 2001 to 2011 as pointed out by Chong et al.(2015). Rapid GDP growth based on energy intensive production and consumption has brought about a rapid growth of coal consumption. For example, China implemented positive fiscal policy to promote the reform of the real estate market at the beginning of the $21^{\text {st }}$ century. The investment in the development of real estate began to increase quickly, with an average annual growth rate of more than 25\% in 2001-2012, which drove the consumption of steel, building material and other energy-intensive products at the same time.

According to earlier research, China's coal demand will continue to grow and it may prove difficult for China to reach a peak in its coal consumption before 2020 (Wang and Li, 2008). However, China's coal consumption growth began slowing down from 2013 largely due to the slowdown of economic growth and the stagnation of energy intensive industries. In 2014, China's coal 
consumption fell by 2.9\% (National Bureau of Statistics of China, 2015). China has made significant efforts to control coal consumption. The latest important effort was made in November 2014, when China and the U.S. issued a Joint Announcement on Climate Change (Xinhua net, 2014). According to the announcement, China intends to achieve a peak in its $\mathrm{CO}_{2}$ emissions around 2030 and to make its best efforts to peak early, and intends to increase the share of non-fossil fuels in primary energy consumption to around $20 \%$ by 2030. It is hard to say whether China`s coal consumption has already peaked in 2013. In a recent study, Hao et al. (2015) pointed out that China’s coal consumption is expected to continue growing at a decreasing rate until 2020 under the benchmark scenario. However, the rate of increase of coal consumption will decrease significantly in the future. With full implementation of its ambitious targets, China may adopt stricter controls to peak coal consumption earlier.

In recent years, the development and utilization of renewable energy for power generation have been paid more attention in China due to the severe environmental problems associated with coal, and it has become an important part of Chinese energy policy (Zhu et al, 2015). Taking China's wind power development for example, China has abundant wind energy resources and ranks third in the world in wind power potential (Zhao et al., 2011). China led the world for the first time with the largest cumulative installed capacity of 44.3 GW of wind power in 2010 (GWEC, 2012), which reached 96.37 GW in 2014, around 27\% of the total global installed capacity of wind power (Xinhua net, 2015). Other renewable energy sources for power generation, such as the biomass power industry, have also achieved rapid growth (Liu et al., 2014).

In 2014, power generation from renewable energy reached 4.3 trillion $\mathrm{kWh}$ and accounted for 22\% of total power generation in China (China National Energy Administration, 2015). Even so, 
the complex Chinese market environment presents significant challenges to power generation from renewable energy (Zhao et al, 2013; Liu et al., 2014). Developing renewable energy will also take a long time for research and development, alongside significant investments (Höök et al., 2012). Therefore, the fuel mix for power generation is still currently dominated by coal, and removing coal from the energy mix is unlikely to be the first choice to reduce greenhouse gas emissions and improve air quality (Bloch et al., 2012).

Against this background, an important option will be to seek ways to utilize current coal resources in an environmentally acceptable manner. Therefore, clean coal technologies would appear to be a clear strategic choice for energy in China. However, clean coal isn't widely used in China at present. The purpose of this study is to analyze the situation and the challenges for implementation of clean coal in China. The remainder of this paper is organized as follows. Section 2 provides a brief review on the development of clean coal technologies in China. The challenges faced in implementing clean coal technologies and their policy implications will be analyzed in Section 3 and Section 4 respectively, and the study will conclude in Section 5.

\section{Development of clean coal technologies in China}

Clean coal technology (CCT) can have many specific meanings. Buchan and Cao (2004) defined clean coal technology as a "technology that, when implemented, improves the environmental performance and efficiency as compared to the current state-of-the art in coal-fired power plants". Clean coal technology generally implies that the plant is more efficient than conventional coal-fired power plants (typically through operating higher temperatures and pressures), or that the plant captures and stores carbon dioxide emitted during operations (CCS), although plants that reduce localized pollutants such as $\mathrm{SO}_{\mathrm{x}}, \mathrm{NO}_{\mathrm{x}}$, particulate matter $\left(\mathrm{PM}_{10}, \mathrm{PM}_{2.5}\right)$ 
and heavy metals such as mercury may also be included in clean coal technologies, while in many jurisdictions the use of desulphurization, $\mathrm{NO}_{\mathrm{x}}$-reduction and scrubbing or filter technologies is effectively standard technology.

Investigation into clean coal technologies started comparatively late in China when contrasted with European and American nations. The USA led in the design and construction of supercritical (SC) and ultra-supercritical (USC) pulverized coal technology in the late 1950s, while Germany started to use supercritical power plants in 1965, and Japan started constructing supercritical plants in the 1970s (Rennings and Smidt, 2010). Korea and Japan remain the leading nations with regards to the use and development of USC technologies, and have the most efficient coal-power fleets in the world, although China has more USC and SC plant capacity in total (IEA, 2012). China only started using supercritical technology in the 1990s with the procurement of ten units from Russia (Horbach et al., 2014).Although clean coal technologies were late in getting off the ground in China, clean coal technology has seen progress over the last two decades (Li, 2010; Xu, 2012) and there have been numerous studies classifying clean coal technologies. In China, CCTs are mainly referring to high efficiency combustion and advanced power generation technologies, coal-tochemicals technologies, IGCC (integrated gasification combined cycle) technologies and CCS (carbon capture and storage) technologies Na et al.(2015). Chen and Xu (2010) similarly divide China's clean coal technologies into four groups, including high efficiency combustion and advanced power generation technologies, coal transformation technologies, IGCC and CCS. Lu et al. (2008) put a total of 18 CCTs into five groups: coal processing, high-efficiency and advanced power generation, coal conversion, clean and efficient comprehensive utilization of coal and 
emissions post reduction treatment. There are four focus CCTs addressed in China's 12th special clean coal plan (2010-2015) for clean coal technology development (MOST, 2012) including advanced coal-based power generation, technological development to generate clean fuels based on coal, post emissions reduction treatment, industrial energy efficiency especially in the iron and steel sector. Although different research puts CCTs in different groups based on different objectives, all of these groups are more or less within the frame work of CCTs in China that range from coal processing to post-combustion treatment (Zhao and Chen,2015).

Advanced coal-based power generation takes the primary place in China’s CCT development. China's power sector has achieved significant progress in technology innovation with the overall efficiency of the coal-power fleet rising from 32\% in 2002 to 36\% in 2012 (IEA, 2013). This is mostly due to the rapid development of SC/USC technology, with the proportion of $>300 \mathrm{MW}$ units increasing as the Chinese government has been effective in regulating the shut-down of smaller, older and less-efficient plants (IEA, 2012). This could reduce approximately $280 \mathrm{Mt} \mathrm{CO}_{2}$ per year (NDRC, 2010). These clean coal technologies applied for power generation mainly including USC, IGCC and CCS are among the key options for China to achieve sustainable development since they are associated with higher efficiency and lower emissions Na et al. (2015). For example, the CCS demonstration project of HUANENG Beijing thermal power plant was officially brought into operation in 2008, and marked the first time the CCS technology has been applied in the electricity field in China. Current research indicates that CCS is an effective way to reduce future emissions in China, with general support of the Chinese government and environmental groups, although further economic and policy support are needed, as are secure locations for storage of the captured emissions (Zeng et al., 2014). 
Power however, is not the only usage of coal - in fact it only accounts for around half of the coal usage in China (IEA, 2013). Besides power, CCTs have to be developed and deployed in many other industrial sectors (Zhao and Chen, 2015). For example, coal and coke for use in steel making (around 15\% of total coal consumption), or for non-metal minerals such as cement for construction (greater than $6 \%$ of consumption) (IEA, 2013). CCTs are particularly vital in these industries, which require high temperature heat that is difficult to substitute with non-fossil-fuels with present technology (McLellan et al. 2012). These also represent large point sources of emissions that are conducive to CCS.

As for generating clean fuels based on coal, coal-to-liquids (CTL) is one of the important applications, and an area where China has been a global leader in technology applications with the most active coal liquefaction program in the world because of its R\&D and demonstration efforts (Liu et al., 2010). CTL developed rapidly during the period from the late 1990s to 2006 in China since the central government was very enthusiastic in promoting the development of the CTL industry at that time (Qi et al., 2012). Coal liquefaction has been seen as a potential substitute for oil products, providing a much larger resource base and potentially cheaper fuel. After 2006, China reversed its coal liquefaction policy and slowed down the rapid expansion of the CTL industry (Rong and Victo, 2011). Gasification is one of the most important links among the coal transformation technologies, producing synthesis gas that can be combusted or further-converted into liquids using Fischer-Tropsch processes or into other gaseous products such as hydrogen (Shoko, et al. 2006). The primary gasification technologies being developed in China are ash agglomerating fluidized-bed coal gasification, non-slagging and slagging two-stage entrained flow coal gasification, two-stage dry feed entrained flow coal gasification, coal-water slurry gasification 
with opposed multi-burners, and coal-water slurry gasification with multiple materials (Chen and $\mathrm{Xu}, 2010)$. Gasification, and in particular integrated gasification combined cycle (IGCC) is one route to improving the efficiency and emissions of electricity generation, but has suffered from low capacity factors due to the level of integration in the past, making some market analysts consider USC technologies as more effective.

Progress in clean coal technology is essential for global GHG emissions reduction, and has contributed to energy savings and emission reductions in China (Lin, 2010). However, there is still significant room for improvement, although significant challenges may lie in the way.

\section{Challenges in China's clean coal utilization}

From the perspective of the industry as a whole, China`s coal industry is facing more challenges now than in previous times, including low competitive capacity, high mortality incidence, poor energy-efficiency and emission-reducing policies (Shen et al., 2012). Clean coal development must be seen within the context of the industry and attendant policy. Although clean coal technologies have witnessed many successes, they aren't widely used in China and face many challenges. The main challenges faced by China in utilizing clean coal arise from management issues which involve the laws and energy administration that will be analyzed in this section.

\section{(1) Enterprises' low enthusiasm in adopting clean coal technology}

The drivers for enterprises to invest in new CCT - whether using coal washing, pollution prevention measures or higher efficiency technologies - must be sufficient to overcome barriers and inertia associated with business-as-usual behavior in order for CCT to be taken up. Currently, despite large scale new entries taking-up SC and USC technologies, there is still a large segment of the coal 
industry that is not proactively adopting CCT. Due to the relatively small present scale of clean coal, a complete industrial supply chain has yet to be formed in China, which both increases the cost of clean coal and reduces the choice of clean coal equipment and products to the enterprise. Therefore, most enterprises still prefer direct combustion when using coal resources (Li and Wang, 2012). Another important factor is that the penalty for breaking regulations is set too low to affect company enthusiasm in adopting clean coal technology. According to current legislation - "Law of the People's Republic of China on the Prevention and Control of Atmospheric Pollution” (CPGPRC,2005) - the biggest fine to be imposed will not be more than 500,000 Yuan for a violation of the regulations. Table 1 shows the legal liability for atmospheric pollution related to coal use. However, the investment cost for clean coal implementation is much higher (Table 2) when compared against the schedule of fines, especially large for small and medium-sized enterprises. Retrofitting of CCT onto older plants can often be impractical, as it reduces the efficiency of generation further and therefore has multiple capital and operational costs to the plant owner. Shortof investing in new plant construction, this is often restrictive to CCT implementation on a purely business case. Moves to affect this cost-benefit balance would be required to strengthen the urgency of businesses to invest.

Unusual to most developed countries, China has a small but significant use of coal in the residential sector for heating (around 3\% of total coal usage) (IEA, 2013). This is a challenging sector to improve implementation of CCT, except perhaps by the implementation of greater combined-heat and power (CHP) in order to improve efficiency. Numerous small-scale emitters are likely to be less efficient and are harder to incorporate CCS (McLellan et al. 2015), so it may be best to discourage such practices where possible. 


\section{(2) Lack of laws and detailed implementation requirement for clean coal utilization}

In legislation and government policy China has promulgated a variety of laws and policies that impact on coal use - for example, the: "Coal Law”, "Energy Conservation Law”, "Coal Industry Policy", and "the 12th Five-Year Plan of coal industry development". However, these laws, regulations and polices lack economic incentives and mandatory requirements (Zhao, 2011).

Current policies related to clean coal technology development - such as policies surrounding R\&D, energy-saving, environmental impacts and policies on comprehensive utilization of resources - are not always compatible with one another (Lu et al., 2008). For example, China encourages the consumption of fine coal with low-sulfur or low-ash content, and encourages and supports the development and popularization of coal cleaning technologies as mentioned in Article 26 of the Law of the People's Republic of China on the Prevention and Control of Atmospheric Pollution (CPGPRC, 2005). However the law lacks a corresponding detailed implementation requirement, which enables CCT development to be avoided in practice to a large degree. Such policies for development of clean coal technology are still at an early stage in China, with a paucity of laws and regulations directing clean coal utilization.

\section{(3) Lack of effective government supervision in coal industry}

Coal mines in China can be divided in to three main categories of ownership including Major State Coal Mines (MSCs), Local State Coal Mines (LSCs) and Township and Village Coal Mines (TVCs). The supervisory system of the coal industry in China can be divided into four levels from State Council to provincial, municipal, and county government, and both central and local governments in China are responsible for the supervision of the coal industry (New China Coal Industry Editorial Board, 2007). MSCs are mostly large mines controlled by the central government 
through the Administration of National Agencies. LSCs are medium-sized ones and provincial, municipal, or county governments operate those, while TVCs are mostly small and operated by townships, communes, or collectives (Shen et al., 2012).

The Development and Reform Commission at a provincial level administrate all of the LSCs and TVCs, however, due to their specific targets, governments at the four levels have different shortterm and long-term interests, where local government cares more about immediate interests for the locality (Andrews et al., 2003). Therefore, in the area of public management, China lacks a unified structure for the governance of the coal industry, with no coordination of clean coal development from the National Energy Department of China resulting in no overall plan and arrangement for clean coal use.

\section{(4) Competing subsidization and investment priorities}

Emissions reduction can be accomplished by various technologies - including CCT and renewables as prime examples. China has had policies subsidising and incentivising renewable energy, which may compete with CCT for investment funding. While this is not necessarily a flaw in policy, it should be investigated to identify the best mix of financial incentives relative to benefits. Electricity also has subsidies, but also capped prices in certain markets (in order to enable access by lower income households). These may need to be abolished, and a more liberalised market created in order to enable power companies to gain sufficient profits to offset new CCT infrastructure costs.

Another important factor to be considered is the impact of the current patterns of economic growth and trade. It has been discussed elsewhere that the current export-oriented economic model has been significantly driving the use of energy in China, and that much of this energy use has been provided by coal (Tang et al. 2015). At the same time, the steel and cement production that has been 
driven by domestic infrastructure construction requirements has slowed, thus potentially reducing coal utilisation in these sectors, though not through CCT. Should this drive further competition in the domestic market (competing for lower demand), it may see the lowest cost competitors survive. Lowest cost could be associated with the most efficient current plants, but is unlikely to be sufficient a driver to invest in CCT upgrades in higher cost facilities.

\section{Policy Implications}

It can be argued, particularly in China, that implementation of clean coal technology should be driven by the government through the functions of public administration. Some policies are suggested as follows:

\section{(1) Strengthen legislation to compel the use of clean coal}

According to the experiences of other nation states, promotion of clean coal development is generally driven by environmental regulation and policy initiatives. For example, the Clean Air Act in the USA and air pollution control policies in the EU have not only the requirement of a detailed time limit and standards for environmental control but also provisions for criminal sanctions against noncompliance (Lu et al., 2008). (There are of course exceptions that have been made, allowing older plants to operate outside regular compliance limits.)

Distinct from other countries where clean coal development is driven by environmental policies, China's clean coal development is primarily driven through the use of technical policies. In order to accelerate clean coal development, China should revisit and revise related laws and environmental policies such as developing stricter emission standards for industries consuming coal, collection of fees on total emissions, imposition of penalties on emissions exceeding regulations, 
development of an emission trading scheme, and collecting environmental taxes. Policy can be tested initially in China's major coal-rich provinces such as Shanxi, Inner Mongolia, particularly revising punishment standards to increase an enterprise' legal costs.

\section{(2) Formulate tax preference policy and financial subsidy policy to encourage clean coal}

\section{utilization}

Sufficient financial support is an important factor for clean coal technology implementation. For example, the total investment in the American clean coal program is 7.14 billion USD, of which the proportion of government funding is about 35\% (Lu et al., 2008). Initially, China should gradually increase financial investment in the clean coal industry from government funding, and classify this industry as a priority development area to adjust economic and industrial structures. At the same time, the development of a clean coal industry should be brought into the overall and longterm development plan for the national economy and society. Secondly, investment policies should be made more attractive to enterprises encouraging the adoption of clean coal technology. For example, incentive policies such as preferential taxation and low-interest rate loans for the introduction of advanced technologies could promote enterprises’ enthusiasm to adopt clean coal technologies. Since the investment cost for clean coal use is high, reliable and stable capital sources are very important for to create an investment climate favourable to the adoption of clean coal technologies (Liang et al., 2013). The government can establish mechanisms for clean coal development that broaden corporate finance channels, including a clean coal development fund and a multi-level finance system that can help reduce the investment threshold of clean coal implementation, especially in small and medium-sized enterprises.

\section{(3) Carry out life-cycle management for coal utilization}


Exploitation and utilization of coal is a full life-cycle process involving the coal industry itself as well as downstream coal-consuming sectors such as the electrical power industry, metallurgical industry, building materials industry and chemical industry. Any omission from the chain will have a significant impact on the environment (Xiao et al., 2005). For example, the mining and processing of coal has the potential to cause a number of burdens on the environmental resources such as air resources, land resources, water resources, if planning and management practices are not in place (Brent 2003,2004). Therefore, clean coal and its development should not just focus on a few processes but be managed throughout its life-cycle. Responsible environmental management practices for the whole life-cycle can improve environmental performances (Mangena and Brent, 2006). Unfortunately, current research in China on this issue is not sufficient, and there is a lack of relevant experience in the practice of life-cycle management. Improving comprehensive utilization efficiencies from the whole coal life-cycle is a clear priority for the future of coal use in China (Tie et al., 2009). China can begin by starting demonstration projects as case studies of whole life cycle management in coal-rich regions to develop important practices, data and experience that can prepare the way for more suitable policy in the future.

\section{(4) Popular pressure for environmental improvement}

Another important avenue for improving the uptake of CCT may be to utilize current popular dissatisfaction with air quality - particularly in major cities. Policies enabling the populace to have active impact on the reduction of emissions by direct financial stakeholding or through community feedback mechanisms that enable the stopping of polluting operations, while perhaps outside the current political structures, could provide a new enforcement process for the government. 
energy sector, while presiding over a meeting of the Central Leading Group on Financial and Economic Affairs on June 13th 2014. As for the coal industry, its core targets are to restore commodity attributes of coal, establish a market structure and market system of effective competition, and change regulation modes of the government. It is imperative for the central government to develop an innovative energy management mechanism, in order to eliminate conflicts-of-interest between the central government and local governments, between coal and power industries, and among different regions.

\section{Concluding remarks}

Cheap coal has been exploited for a long time with little or no consideration for environmental costs to China, and the social environmental benefits of clean coal utilization are not fully reflected in the price of coal. Although there have been many successes for clean coal technologies internationally, China has witnessed limited dissemination of these technologies. The challenges China faces in implementing clean coal from a management perspective can be mainly divided into two parts. The first are the legal liabilities for atmospheric pollution related to coal use are too low in China, and the lack of laws and regulations to support clean coal use. The second is that China lacks unified structures for governance within the coal industry and there is no coordination of clean coal development from the National Energy Department in China resulting in no overall plan for clean coal propagation. Policies for clean coal are still in their infancy in China, and the absence of laws and detailed implementation requirements for clean coal need to be resolved to enable a more rapid acceleration of clean coal developments in China.

In recent years, the severe haze that continues to plague many areas of China has done great harm to the population's health (Ye et al., 2001). Currently, environmental pollution problems have 
gained the widespread attention of the populace of China. Against such a background, China should take advantage of this opportunity to regain the initiative to raise people's awareness of clean coal products, and improve corporate enthusiasm for clean coal use. Only in this way may the clean development and use of coal be truly promoted by China through legislation, administration reform and participation of all citizens.

\section{Acknowledgements}

The authors appreciate the following funding that made this study possible: National Natural Science Foundation of China (71303258, 71373285), National Social Science Funds of China (13\&ZD159), Research Fund for the Doctoral Program of Higher Education of China (20120007120015), MOE (Ministry of Education in China) Project of Humanities and Social Sciences (13YJC630148), and Science Foundation of China University of Petroleum, Beijing (ZX20150130) for sponsoring this joint research.

ReferencesAndrews S.P., Yang M., Shen L., Cao S., 2003. The regulation of China's township and village coal mines: a study of complexity and ineffectiveness. Journal of Cleaner Production, 11(2):185-196.

Bloch H., RafiqS., SalimR,2012. Coal consumption, $\mathrm{CO}_{2}$ emission and economic growth in China: Empirical evidence and policy responses. Energy Economics, 34(2), 518-528.

Bloch H., Rafiq S., Salim R., 2015. Economic growth with coal, oil and renewable energy consumption in China: Prospects for fuel substitution. Economic Modelling, 44(1): 104-115.

Boden T. A., Marland G., Andres R. J., 2013. Global, Regional, and National Fossil-Fuel $\mathrm{CO}_{2}$ Emissions. Carbon Dioxide Information Analysis Center, Oak Ridge National Laboratory, U.S. Department of Energy, Oak Ridge, Tenn., U.S.A. 
Brent A.C., 2003.A proposed lifecycle impact assessment framework for South Africa from available environmental data. South African Journal of Science, 99 (3):115-122

Brent A.C., 2004. A Life Cycle Impact Assessment procedure with resource groups as areas of protection. The International Journal of Life Cycle Assessment, 9 (3):172-179.

Buchan B., Cao C., 2004.Coal-fired generation: proven and developing technologies. Office of Market Monitoring and Strategic Analysis. Florida Public Service Commission. http://www.naruc.org/associations/1773/files/definition.pdf

Chen W.Y., Xu R.N,„2010. Clean coal technology development in China. Energy Policy,38(5): 2123-2130.

China National Energy Administration,2015. Power generation from renewable energy reaches 4.3 trillion kWh in 2014. http://newenergy.in-en.com/html/newenergy-2230860.shtml

Chong C.H., Ma L.W., Li Z., Ni W.D., Song S.Z.,2015.Logarithmic mean Divisia index (LMDI) decomposition of coal consumption in China based on the energy allocation diagram of coal flows.Energy.85(1):366-378.

CPGPRC (the Central people's government of the people's republic of China), 2005. Law of the People's Republic of China on the Prevention and Control of Atmospheric Pollution.http://www.gov.cn/ziliao/flfg/2005-08/05/content_20945.htm

Govindaraju V.G.R. C., Tang C.F., 2013. The dynamiclinks between $\mathrm{CO}_{2}$ emissions, economic growth and coal consumption in China and India. Applied Energy, 104(4): 310-318.

GWEC.,2012. Global Wind Report, Annual market update 2011. Global Wind Energy Council, Brussels, Belgium.

Hao Y., Zhang Z.Y., Liao H., Wei Y.M.,2015.China's farewell to coal: A forecast of coal 
consumption through 2020. Energy Policy. 86(11):444-455.

He Y.Q., Lao G.H., Osuch C.E., Zuo W.R., Wen B.F., 2008. Co-integration-based analysis of energy assurance for steady economic growth in China. Journal of China University of Mining and Technology.18 (2):250-254.

Höök M., Li J.C, JohanssonK., SnowdenS.,2012. Growth rates of global energy systems and future outlooks, Natural Resources Research, 21(1): 23-41.

Höök M., Tang X., Pang X.Q., Aleklett K.,2010. Development journey and outlook of Chinese giant oilfields. Petroleum Exploration and Development.37(2):237-249.

Horbach J., Chen Q., Rennings K., Vögele S., 2014.Do lead markets for clean coal technology follow market demand? A case study for China, Germany, Japan and the US.Environmental Innovation and Societal Transitions, 10(3):42-58.

Li G.M., Wang X.G.,2012. Present situation and the future of clean coal energy development and utilization in China(in Chinese). Economic Review, (12):115-118.

Li H.Y,2010. General situation of development of China clean coal technology(in Chinese). Technology innovation and productivity, (9):63-65.

Li J.C., DongX.C., ShangguanJ,.HöökM., 2011. Forecasting the growth of China’s natural gas consumption. Energy, 36(3):1380-1385.

Li M.N., Zhang L.L., 2014. Haze in China: Current and future challenges. Environmental Pollution, 189(6): 85-86.

Liang X.Y., Wang Z.H., Zhou Z.J., Huang Z.Y., Zhou J.H., Cen K.F., 2013.Up-to-date life cycle assessment and comparison study of clean coal power generation technologies in China. Journal of Cleaner Production, 39(1):24-31. 
Lin B.Q, Wang, T., 2012. Forecasting natural gas supply in China: Production peak and import trends. Energy Policy, 49(10): 225-233.

Lin Y., 2010.Dynamics of clean coal-fired power generation development in China. Energy Policy,51(12):138-142.

Liu J.C., Wang S.J., Wei Q.S., Yan S.L., 2014. Present situation, problems and solutions of China's biomass power generation industry. Energy Policy.70(7):144-151.

Liu Z., Shi S., Li Y.,2010. Coal liquefaction technologies-development in China and challenges in chemical reaction engineering. Chemical Engineering Science, 65(1):12-17.Lu X., Yu Z.F., Wu L.X., Yu J., Chen G.F., Fan M.H., 2008. Policy study on development and utilization of clean coal technology in China. Fuel Processing Technology. 89(4): 475-484.

Ma,H.Y.,Oxley,L., Gibson J.,2010. China’s energy economy: A survey of the literature. Economic Systems,34(2):105-132.Mangena S.J., Brent A.C., 2006.Application of a Life Cycle Impact Assessment framework to evaluate and compare environmental performances with economic values of supplied coal products. Journal of Cleaner Production. 14(12-13):1071-1084.

MOST(Ministry of Science and Technology), 2012. 12th special plan for clean coal technology development. http://www.most.gov.cn/fggw/zfwj/zfwj2012/201204/t20120424_93882.htmNa C.N., Yuan J.H.,Xu Y.,Hu Z.,2015. Penetration of clean coal technology and its impact on China's power industry. Energy Strategy Reviews. 7:1-8.National Bureau of Statistics of China,2014. China energy statistical yearbook 2014. China Statistics Press.

NDRC (National Development and Reform Commission), 2007.Renewable energy medium and long-term development plan. http://www.gov.cn/zwgk/2007-09/05/content_738243.htm

NDRC (National Development and Reform Commission),2010. China's Policies and Actions for 
Addressing Climate Change-The Progress Report 2010.

http://www.cchina.gov.cn/WebSite/CCChina/UpFile/File927.pdf

New China Coal Industry Editorial Board. New China Coal Industry. Ocean Press, Beijing (2007)

in Chinese.

Pang X.Q., Zhao L., Feng L.Y., Meng Q.Y.,Tang X., Li J.C.,2009.The evolution and present status of the study on peak oil in China. Petroleum Science. 2(6):217-224.

Qi T.Y., Zhou L., Zhang X.L., Ren X.K.,2012. Regional economic output and employment impact of coal-to-liquids (CTL) industry in China: An input-output analysis. Energy.46(1):259-263.

Rennings K., Smidt W., 2010. A lead market approach towards the emergence and diffusion of coal-fired power plant technology. Political Economy, XXVII (2): 301-327.

Rong F., Victor D.G., 2011.Coal liquefaction policy in China: explaining the policy reversal since 2006. Energy Policy, 39(12):8175-8184.

Shealy M.,Dorian J.P., 2010.Growing Chinese coal use: Dramatic resource and environmental implications. Energy Policy, 38(5): 2116-2122.

Shen L., Gao T.M., Cheng X., 2012. China's coal policy since 1979: A brief overview. Energy Policy. 40(1): 274-281.

Sheng Y., Shi X.P., Zhang D.D., 2014. Economic growth, regional disparities and energy demand in China. Energy Policy, 71(8):31-39.

Tang X., Zhang B.S., Höök M., Feng L.Y.,2010.Forecast of oil reserves and production in Daqing oilfield of China. Energy.35(7):3097-3102.

Tie X., Wu D., Brasseur G., 2009.Lung cancer mortality and exposure to atmospheric aerosol particles in Guangzhou, China. Atmospheric Environment, 43 (14):2375-2377. 
Wang J.L., 2014. Resource constrained global fossil fuels supply and its impacts on climate change (in Chinese). China Universityof Petroleum, Beijing, Ph.D thesis.

Wang Y., Li J.W., 2008.China's present situation of coal consumption and future coal demand forecast. China Population Resources and Environment, 18(3): 152-155.

Xiao B.,Zhang AL.,Chen G.F.,2005.Life cycle inventory of clean coal-fired power generation in China. Clean Coal Technology,11(2):1-4.

Xinhua net, 2015.China's increased installed capacity of wind power hit new record in 2014. http://news.xinhuanet.com/2015-02/12/c_1114355097.htm

Xu H.X., 2012.A discussion on China's clean coal utilization strategy (in Chinese).Sino-Global Energy,17(4):1-13.

Ye X., Ma Z., Zhang J., Du H., Chen J., Chen H., 2011. Important role of ammonia on haze formation in shanghai, Environmental Research Letters, 6 (2):1-5.

You C.F., Xu X.C.,2010.Coal combustion and its pollution control in China. Energy, 35(11):44674472.

Zeng M., Ouyang S.J., Zhang Y.J., Shi H., 2014. CCS technology development in China: Status, problems and countermeasures-Based on SWOT analysis. Renewable and Sustainable Energy Reviews.39(11):604-616.

Zhao J.F., 2011. Analysis and policy recommendation on coal industry cleansing fromthe perspective of low carbon economy (in Chinese). Journal of China coal society, 36(3):514-518.

Zhao G.L., Chen S., 2015. Greenhouse gas emissions reduction in China by cleaner coal technology towards 2020.Energy Strategy Reviews. 7:63-70.

Zhao Z.Y., Hong Y., Jian Z., Tian Y.X., Zillante G..,2013. A critical review of factors affecting 
the wind power generation industry in China. Renewable and Sustainable Energy Reviews. 19(3):499-508.

Zhao Z.Y., Zuo J., Fan L.L., Zillante G.,2011. Impacts of renewable energy regulations on the structure of power generation in China-a critical analysis. Renewable Energy.36 (1): 24-30.

Zhu Z., Zhang D., Peggy M., Zhang X.L.,2015. Electricity generation costs of concentrated solar power technologies in China based on operational plants. Energy.89(9):65-74.

National Bureau of Statistics of China, 2015. Statistical communique of the People's Republic of China on the 2014 National Economic and Social Development. http://www.stats.gov.cn/tjsj/zxfb/201502/t20150226_685799.html

Xinhua net, 2014. U.S.-China Joint Announcement on Climate Change. http://news.xinhuanet.com/2014-11/12/c_1113221744.htm

IEA, 2012.Technology Roadmap: High-Efficiency, Low-Emissions Coal-Fired Power Generation. Paris, France, International Energy Agency.

IEA ,2013. Energy balances of non-OECD countries. Paris, France, International Energy Agency.

McLellan, B. C., G. D. Corder, D. P. Giurco and K. N. Ishihara ,2012. Renewable energy in the minerals industry: A review of global potential. Journal of Cleaner Production. 32: 32-44.

McLellan, B. C., N. Florin, D. P. Giurco, Y. Kishita, K. Itaoka and T. Tezuka ,2015. Decentralised energy futures: the changing emissions reduction landscape. The 22nd CIRP conference on Life Cycle Engineering. S. Kara, W. Li, S. Vongbunyong and S. Ibbotson. Sydney, Australia.

Shoko, E., B. McLellan, A. L. Dicks and J. C. D. da Costa ,2006. Hydrogen from coal: 
Production and utilisation technologies. International Journal of Coal Geology.65(3-4): 213-222.

Tang, X., B. McLellan, S. Snowden, B. Zhang and M. Höök, 2015. Dilemmas for China:

Energy, Economy and Environment. Sustainability. 7(5): 5508-5520. 